\title{
A Comparison of The Results of The Training Effect Using Repeated Speed and Handling Accuracy Tests for The Russian Shinik Football Club School Players Aged 14-15 Years
}

\author{
Sajad Mohsen Ali, Asst. Prof. Dr. Naji Kazem Ali \\ University of Baghdad / College of Physical Education and Sports Sciences
}

DOI: $10.37648 / \mathrm{ijrssh} . v 10 \mathrm{i} 04.032$

Received:09 ${ }^{\text {th }}$ August, 2020; Accepted:10 ${ }^{\text {th }}$ September, 2020; Published: 14th December, 2020

\begin{abstract}
The aim of the research was to establish a comparative study of the effect of a training curriculum used for a certain period and to know the results of the pre and post tests and the difference between them. As for the imposition of the research, it was the presence of statistically significant differences in the results of the tests in favor of the moral tests.

The third chapter contained the research methodology and its field procedures, and the research methodology was experimental by comparative method for its suitability to the mentioned research problem. And analyze it.

The researcher concluded through the fifth and last chapters that there are significant statistical differences for the dimensional research tests.
\end{abstract}

\section{INTRODUCTION}

$\mathrm{t}$ can be seen that the fitness of a football player finds its special expression mainly in characteristics such as high start-up speed, accuracy of goal scoring and winning, ability to jump, tackle and cut, fast endurance with and without the ball, lack of level and actual performance, and the speed of moving from the defensive third to the offensive third And vice versa, as well as the absence of forced substitutions and the entry of therapists due to convulsions or injuries that occur as a result of physical weakness or inability to play a full match with high physical effort, and good physical fitness solves these problems for football players, the most prominent of which is the failure to complete the training unit sometimes due to the difficulty of training on The player as well as the player who does not have deficiencies in these aspects that are required by the game, and also on the correct selection and selection of the player to represent the team, and we must remember that the performance and movements of football players change in terms of their nature and in terms of the circumstances of the match and therefore resistance to fatigue is the indicator that physical fitness is good For a player at all times of the match, especially in the second half, and as a general rule in the training process, the tasks of general and special physical training are Directly related to the level of the player, and when repeated endurance exercises have a positive effect on the development of strength and speed endurance for players, their abilities to resist fatigue will develop with an improvement in anaerobic endurance, especially in the lactic-phosphogenic acid system, with an improvement in their resistance to the effects of increasing the concentration of lactic acid from the muscle fiber into the stream Blood, which reduces its negative effect in hindering the continuation of motor 
performance and delaying the emergence of symptoms of fatigue.

And The aim of the research is to compare the results of some tests of anaerobic endurance, handling accuracy, and pre- and dimensional scoring accuracy of the Russian Shinik Football Club school players aged 14-15 years of the research sample.

And if the research assumed, there are significant statistical differences between the results of the values of some tests of anaerobic endurance, handling accuracy, and pre- and dimensional scoring accuracy for players of the Russian Shenk Football Club School of football aged 14-15 years and in favor of post-tests.

The areas of research are

- The human domain

A sample of (20) players from the Russian Shinik Football Club School, ages 14-15, for the 2019-2020 sports season. temporal domain -

In the period from 3/2/2020 to 3/18/2020 in Russia spatial domain -

Greater Russia - Yaroslavl, Shinik International Stadium.

\section{MATERIALS AND METHODS:}

\section{Research Methodology:}

The researcher used the descriptive method in the survey method, due to its relevance to the nature of the research problem.

\section{Search community and sample:}

The community of origin are young football players aged 14-15 years, and the first research community is the Russian Shinik Club, and the research sample is the team at ages 14-15 and the sample number is (20) players. The second community for research is the National Center for the Care of Sports Talent in Football and that the sample The research is the team between the ages of 14-15 years and their number (20) players

\section{Means of gathering information, tools and devices used in research:}

Devices, tools and means of gathering information used in the research
: The researcher used the following tools and devices Devices and tools:

- The internet 5 barriers with a height of $74 \mathrm{~cm}$ 20signs, $20 \mathrm{~cm}$ high Footballs, 5 types (NIKE-JAKO) Distance measuring unit (FITT) length (10 meters) 4)whistles (DOLFIN CANON D 80 camera (x1) (Lenovo) electronic computer, 1 count Stopwatch type (XL-O13) x5 -

Height and weight measuring device Means of gathering information:

Arab and foreign sources -

Personal interviews with specialists and experts-

Helping staff

Data collection forms and test results in Arabic and Russian -

Paper and pen questionnaire forms and electronically -

\section{Field research procedures:}

Handling accuracy of movement

Test name: Handling accuracy

Test objective: to measure handling accuracy with tolerances

Test instruments: a playground, 11 signs, 6 balls, a stopwatch, a whistle

Performance explanation: The test player stands at the starting point shown below in the picture, and after hearing the whistle he runs without a ball and takes the ball and runs with it and tricks he reaches the two figures on the email he hand to the two opposite figures, and then he runs again without a ball to take a second ball and goes with it to the opposite two people and handles it to enter between the two characters Interviews, as well as repeat the same process at the two figures on the left, then repeat the same thing as it started three times also until he completes 6 balls within 50 seconds only and fails in the test. Everyone who did not complete 6 balls also calculates the number of correct manipulations that entered between the two figures at a distance of 20 meters for each side.

The player is given two attempts and the best is taken 
Uses the law of fits for accuracy = valid attempts to calculate the final score Performance time

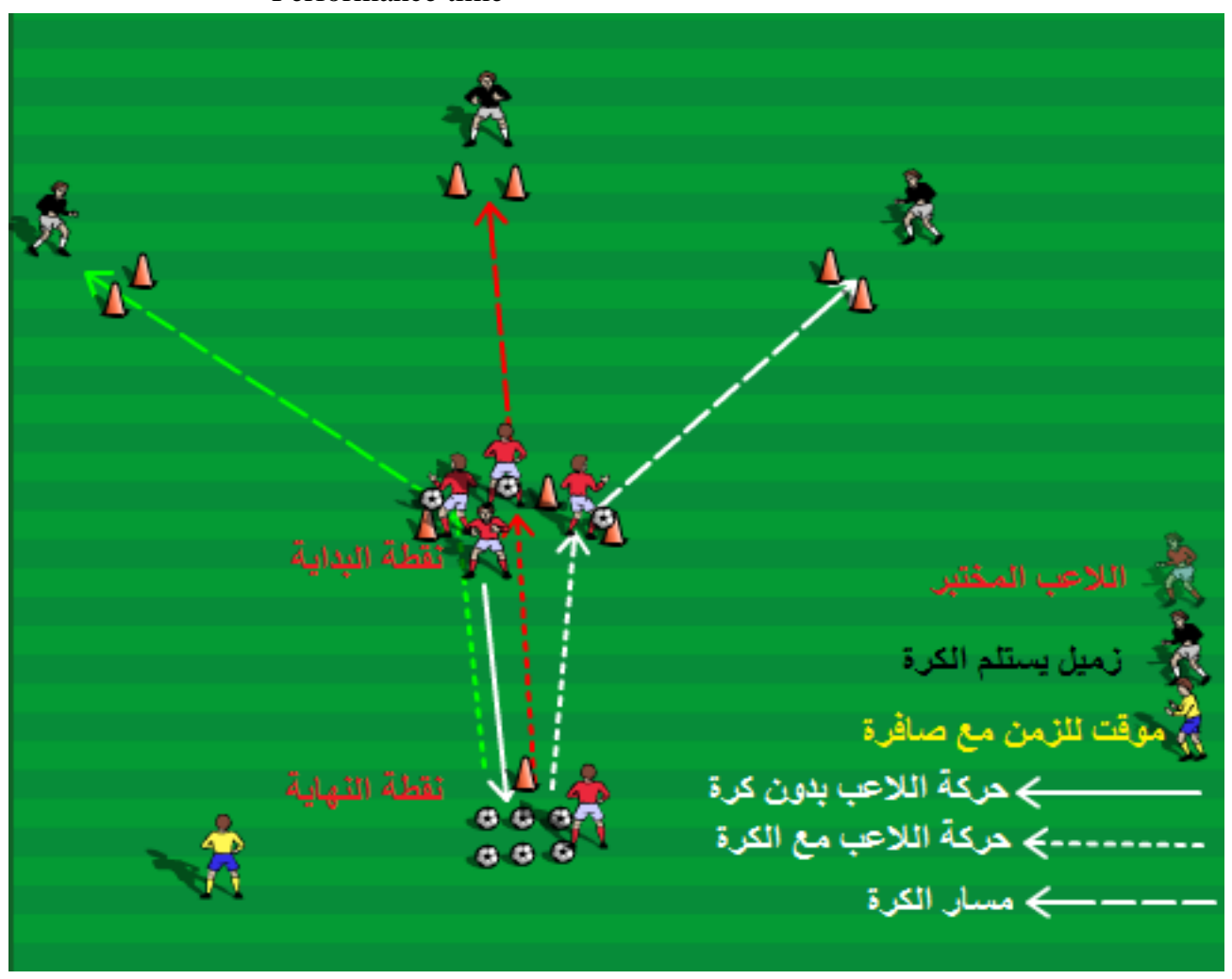

Figure (1) shows a drawing of the handling accuracy test

Test name: withstand repeat speed

Objective of the test: to measure the anaerobic endurance of football players 14-15 years Test instruments: stopwatches, whistle, start and end line, FITT, football field Physiological purpose: to measure anaerobic anaerobic tolerance

Method of performance: The player stands on a line and after hearing the whistle, he starts forward at the maximum speed for a distance of 40 meters and returns on foot to the starting point from which he ran and starts again after the end of the rest (1 minute) until he completes and repeats the player 5 iterations and each repetition is timed separately by a stopwatch and Another stopwatch for timing the rest. It should not pass the 6 seconds in performance with all iterations. The fifth repetition time is calculated as a benchmark for the test

More than one player can be tested according to the presence of the number of timers and the support team. 


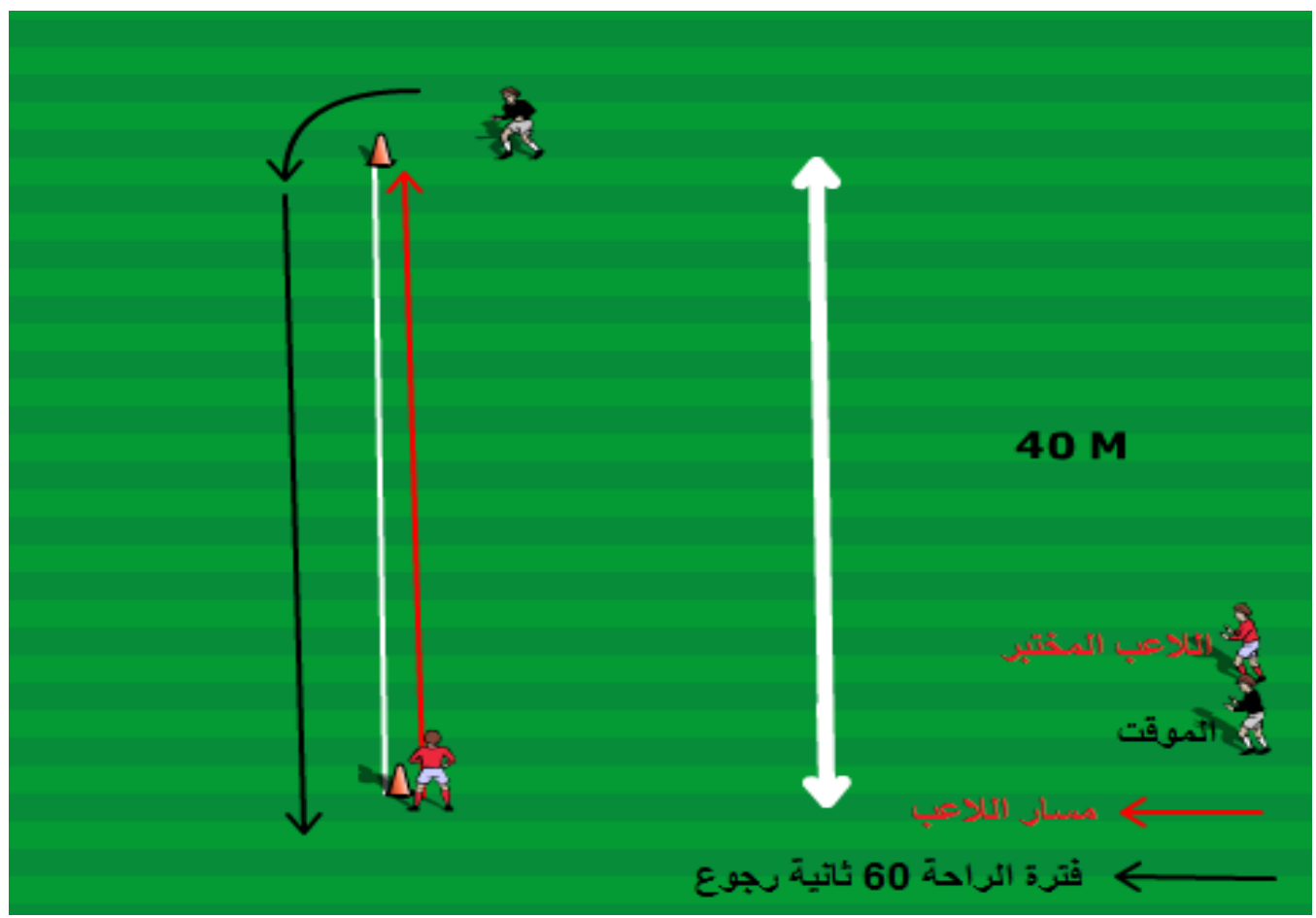

Figure (2) showing a drawing of the repeat speed endurance test

\section{: Exploration Experience}

The researcher began to conduct the reconnaissance experiment in Russia on 2/2/2020

\section{:Main experience}

It also appeared in the main experiment consisting of the pre-tests of the Russian Shinik Club on 3/2/2020 and monitoring the training curriculum used by the coaches during a period of 45 days, after which the post-tests were conducted on 3/18/2020 and the training curriculum was included in the research

\section{:Statistical means}

The researcher used the (spss) system and an excel system to extract the statistical transactions. Whenever he achieved the results of the research, as explained by Hopkins and Class, "the statistical methods help researchers in describing the data and drawing conclusions for large amounts of data as well as in studying the causal relationships" which he obtained using the means next :

Arithmetic mean-

Mediator-

vein-

standard deviation-

variance -

- coefficient of dispersion

T-test for correlated samples -

The rate of development -

The percentage -

\section{RESULT AND DISCUSSION:}

Presentation, analysis and discussion of the pre-examination results of the Russian Shinik Club School 


\begin{tabular}{|l|l|l|l|l|l|l|l|}
\hline $\begin{array}{l}\text { Dispersion } \\
\text { coefficient }\end{array}$ & variance & Vein & mediator & $\begin{array}{l}\text { standard } \\
\text { deviation }\end{array}$ & $\begin{array}{l}\text { Arithmetic } \\
\text { mean }\end{array}$ & the test & sequence \\
\hline 0,046 & 0,069 & 6 & 5,777 & 0,246 & 5,762 & $\begin{array}{l}\text { Withstand repeat } \\
\text { speed }\end{array}$ & 1 \\
\hline 0,524 & 0,001 & 0,08 & 0,064 & 0,033 & 0,062 & Handling accuracy & 2 \\
\hline
\end{tabular}

Table (1) statistical ratios for the pre-tests

From the above table, the value of the arithmetic mean, standard deviation, median, mode, variance, and dispersion coefficient for all pre-search tests, which numbered 6 tests, is evident. Mode 6 , variance 0.069 , the dispersion factor 0.046 , while the values of the second pre-test titled (Handling Accuracy) were the arithmetic mean 0.056, the standard deviation value 0.034, the median value 0.062 , the mode value zero, the variance 0.001 , and the value of the dispersion coefficient. 0.618.

Presentation, analysis and discussion of the post-test results of the Russian Shinik Club School

\begin{tabular}{|l|l|l|l|l|l|l|l|}
\hline $\begin{array}{l}\text { Dispersion } \\
\text { coefficient }\end{array}$ & variance & Vein & mediator & $\begin{array}{l}\text { standard } \\
\text { deviation }\end{array}$ & $\begin{array}{l}\text { Arithmetic } \\
\text { mean }\end{array}$ & the test & sequence \\
\hline 0,050 & 0,080 & 5,72 & 5,72 & 0,260 & 5,635 & $\begin{array}{l}\text { Withstand repeat } \\
\text { speed }\end{array}$ & 1 \\
\hline 0,411 & 0,0007 & - & 0,063 & 0,016 & 0,078 & Handling accuracy & 2 \\
\hline
\end{tabular}

Table (3) the statistical ratios for the post-tests

From the above table, the value of the arithmetic mean, standard deviation, median, mode, variance, and dispersion coefficient of all dimension research tests, which numbered 6 tests, becomes clear where the values of the first post-test titled (bearing repeat velocity) were the arithmetic mean 5.635, standard deviation 0.260 , and the median 5.72 The mode is 5.72 , the variance is 0.080 , the dispersion factor is 0.050 , while the values of the second post-test titled (Handling Accuracy) were the arithmetic mean 0.078 , the standard deviation value 0.016 , the median value 0.063 , the parameter value 0,007 , the variance 0,007 and the value of The dispersion factor is 0.411 .

The percentage of development for the sample of the Russian Shinik School Club between the 1-1-2-4 pre-tests and the posttest:

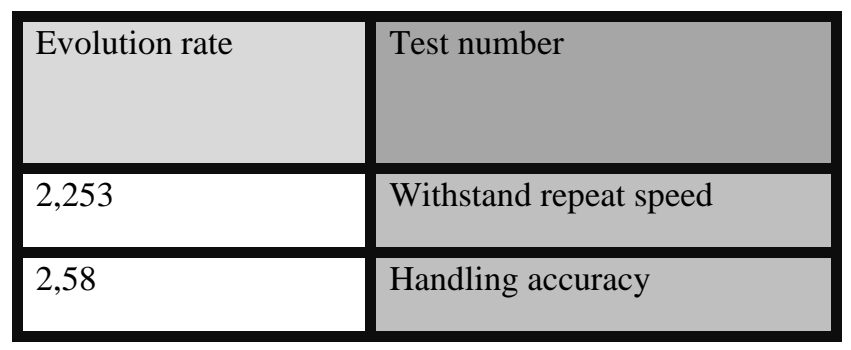

From the above table it becomes clear to us the development rates of the Russian Shinik School Club, where the differences between the pre and post tests, the difference between the pre and post tests for the first test (withstand repeat speed) is 2,253\% and the rate of development in the second test (handling accuracy) $2.58 \%$.

\section{CONCLUSIONS:}

- The existence of an actual effect of the training curriculum used between the pre and post test periods, and this was evidenced by the statistical results. 
- There was a percentage of improvement in the results of the Russian Shinik School's tests for soccer players aged 14-15 years, as the rate of development of the tests reached:

Evolution ratio test name

2,253 repeat speed bearing

2,58 Handling accuracy

\section{ENDORSEMENT:}

- The researcher recommends the necessity of applying modern training curricula in Iraq for young ages in football in order to develop and grow properly as the rest of the developed countries work.

- Holding experimental matches for football schools in Iraq with football schools in these developed countries for the purpose of friction and knowledge of playing methods and abilities.

\section{REFERENCES:}

1- Андреев, С. Н. Играй в футбол: теория и практика физической культуры / С. Н. Андреев. - М. : Просвещение 1999. $-141 \mathrm{c}$.

- Абдулова А.М., Орлова Р.В., Теннова В.П., Иена Е.Б., Шенкмана С.Б., Болотников П.Г. Книга легкоатлета. - М., Физкультура и спорт, (2001г).Тестирование и контроль подготовленности футболистов,Общая характеристика тестов определения двигательных способностей футболистов,с 22 .

- 1Hopkins, Kenneth d. and Class, Ganev (biostatistics for behavioral sciences) Englewood cliffs, New jersy : printers hall inc , 1978, p 30 .

- Ali Samoum Al-Fartousi: Principles of Statistical Methods in Physical Education, Baghdad, House of Books and Archives, 2016, p65.. 